\title{
Initiatives for AtTracting AND Retaining FEMAle StUdents IN MECHANiCAL ENGINEERING
}

\author{
Aezeden O. Mohamed \\ Faculty of Engineering and Applied Science, Memorial University, St. John's, NL, Canada, AlB 3X5 \\ amohamed@mun.ca
}

\begin{abstract}
It is well known that female students are underrepresented in several engineering disciplines, for example, in mechanical and manufacturing engineering.

These disciplines are not benefitting as much as otherwise possible through the increase of student diversity and higher participation rates by women. For example, engineered products designed by men may have a bias towards features that are potentially more attractive and valued by males. With more female input into an engineering design, products can better represent a wider proportion of the population with improved sales as a result. Better gender diversity in the workplace also brings benefits to the work environment.

This paper discusses a number of concepts in materials and manufacturing related courses at Memorial University which aim to improve student diversity, retention and interest among women in engineering.
\end{abstract}

Keywords: Female students; gears; image; logo; mechanical engineering.

\section{INTRODUCTION}

Recent data indicates that the Faculty of Engineering and Applied Science at Memorial University has, at 29\%, the highest proportion of female first-year undergraduate students among Canada's major engineering schools. In total among all engineering schools in Canada, the absolute numbers of female engineering students have dropped by $7 \%$ over the past five years, while those of their male peers have increased by $14.6 \%$ [1]. Since 2001, the proportion of female engineering students has dropped nearly every year, for example, to $17.3 \%$ in 2007 , and to $17.1 \%$ in 2008 [1].

Over the past five or more years, female students have been consistently better represented in four engineering disciplines: chemical, biosystems, environmental, and geological engineering. Female enrolment has been the highest in environmental engineering (36.7\%) and chemical engineering (36.2\%) [2]. Females also made up nearly one-third of enrolment in biosystems engineering $(32.9 \%)$ and geological engineering (31.7\%). The lowest concentrations of female students in past years were in software engineering $(9.6 \%$ female $)$ computer engineering $(9.7 \%)$, and mechanical engineering (10.3\%) [2].

At the graduate level, the percentage of female students in engineering has increased from $20.7 \%$ in 2006 to $21.1 \%$ in 2007 [2]. This small increase in the number of female graduate students occurred at the same time as a small decrease in male graduate students.

Engineering faculties in Canada recognize the importance of attracting more females to faculty positions and there have been increases there. However, as noted above, female enrolments at the undergraduate level has generally been steady or trending downward.

The Faculty of Engineering and Applied Science at Memorial University has developed a 5-year strategic plan to attract and encourage more women to study engineering. If products and technological innovations are designed and undertaken with the input of more female engineers, the products would better represent a broader cross-section of society, and likely improve sales. More female engineers' perspectives are therefore sought, together with those of male engineers, in designing and manufacturing of products, among other engineering activities.

Design input from a greater diversity of engineers in design groups, manufacturing processes, and strategic planning for design and manufacturing will lead to greater diversity of product manufacturing.

This paper discusses a number of concepts in materials and manufacturing related courses at Memorial University which aim to improve student diversity, retention and interest among females in engineering and, over time, for these areas to become a more traditional career option for females.

\section{FEMALE STUDENT PREFERENCES}

One question that is often asked is, "Why is there a higher percentage of female students in the medical professions (medicine, pharmacy, dentistry, nursing) social sciences (social work) and education (teachers) than engineering?" This situation applies to many countries regardless of the traditions and cultures. As 
noted above, female students in engineering generally comprise much less than $50 \%$ of the total student body, regardless of the country, culture and traditions.

These careers are seen to have a larger component requiring communication and interpersonal interactions both during the degree programs and subsequent careers. For example, the physician has to communicate frequently with patients both while studying and when in the profession. The same holds true for school teachers. Human interaction is clearly seen by society as very important in these careers.

In engineering programs and the engineering profession, tasks are often perceived by the general public as math and science-based with specific design projects employing this knowledge. Many of these design tasks are often accomplished by working with computers (numerical models, drawings) or by using other machines and tools.

Of course, there are frequent communications aspects involving others people in the engineering profession, however these elements may not be the image of engineering from the perspective of the general public.

The communications are often predominantly between engineers in the design phase. In particular, engineering students are seen to be largely communicating within their own student groups and not to the same extent with clients in the general public in a way that is found in medical, nursing, social work or other professions. But such interactions are not absent and should be given more emphasis in promoting engineering to females, e.g. design projects involving input from industry and solving community-based problems.

\section{ENCOURAGEMENT TO STUDY ENGINEERING}

Families with engineers often provide awareness and encouragement to their children to consider engineering. For females in engineering, in particular, family support is important from the pre-university level onward. Parents provide their daughters with an awareness of engineering as a good career choice and this encouragement is important.

A past study has reported that female students in engineering receive more parental support than their peers in any other discipline [3]. Parents' expectations for their daughters' values, grades, and work ethic are higher when their daughters choose engineering [4]. The parents of female engineers found that their mothers are more highly educated than parents of male engineers or parents of female professionals in other fields [5]. Girls are more likely to maintain their science and math studies as they grow older during their education than girls whose families adhere more closely to traditional gender roles [6].

Many high school students have no idea what an engineer is or does. Some high school girls think of engineers (in particular mechanical and manufacturing engineers) are labourers or technicians and believe that much physical strength is required to handle the tools and machines. There is also a common misconception of dirty and dangerous working conditions.

Female students who choose to study engineering during high school often do so because of some family members, relatives, or friends who are in engineering or are successful engineers. But for those who do not have any engineering relatives or any connection to engineers, their understanding about engineering may be very stereotyped. These misconceptions of engineering need to be corrected for more successful recruitment of women to engineering.

So it is important to raise awareness of engineering among high school students and students of even a younger age. High school administrators can take the initiative and provide opportunities for teachers in their schools to learn more about engineering and to talk to their classes about famous female engineers. For instance, Stephanie Louise Kwolek discovered Kevlar and used it to make bulletproof vests, radial tires, airplane fuselages and fibre optic cables. Lillian Gilbreth invented human factors engineering and ergonomic design and she is known as the "mother of modern management" [7]. There are countless other examples.

Changing the cultural norms in high schools is not a "quick fix" and will take time. At Memorial University, innovative ways of attracting more female students to engineering include several engineering scholarships and initiatives at the undergraduate level for female students.

In order to prepare our incoming students for the engineering profession, we require them to participate in a number of introductory hands-on design courses. In particular, this includes our introductory Graphics and Design ENGI-1030 and Production Technology ENGI3941 courses. These courses, in particular, provide students with the necessary design skills to begin fundamental engineering and manufacturing courses. In addition, they serve as motivation for the rigorous upcoming mechanical and manufacturing courses to come.

Mechanical and manufacturing engineering disciplines have many sub-areas that overlap with other engineering disciplines. They have elements that are combinations of other engineering disciplines. For example, mechanical and manufacturing engineering courses have topics found in other engineering fields such as chemical, biotechnology, civil, and electrical and computer engineering. Examples are robotics (electrical and computer engineering), corrosion and materials 
(chemical engineering), strength and fracture of metallic structures (civil engineering), design manufacturing (design engineering), engineering economics (engineering management), biomaterial, biomedical, and tissue engineering (bioengineering / biomedical engineering), and mechatronics (involving both mechanical and electronical engineering). Mechanical and manufacturing engineering provides a broad engineering background and opens up a wide range of engineering careers.

The idea of working in what may be perceived to be a predominantly male work environment is not appealing to many women. Unfortunately, some women who have graduated from engineering and went into the engineering profession have found their workplaces sexist. This experience may be passed on to younger girls who might be thinking about engineering. The way in which females are treated in a male-dominated industry can have a significant impact in discouraging young women to consider engineering. When one asks female students why they chose engineering, they often refer to the challenge and the opportunity to be a pioneer, the challenge of mastering difficult and complex issues, solving practical problems, and creating things that work [8].

Talented women who pursue engineering are often at or near the top of their class and rise to the challenge, sometimes despite sexist comments and attitudes, and salary discrepancies that together have, in some instances, made the working environment more difficult for women [8].

A woman engineer is often underestimated by her male colleagues. It is important to create, promote and ensure a positive and inclusive environment for women engineers. Female engineers must be given all of the equal opportunities at work such as training and assignments as their male counterparts. Even when the atmosphere for females in high schools and universities is nondiscriminatory and a level playing field, it will still be challenging to attract female students into mechanical engineering unless industry also improves the environment for female engineers.

Industry-university engineering partnerships have been developed extensively at Memorial University. For example, Memorial University has a unique co-operative engineering program that not only provides students with engineering training and experience but also enables female engineering students to overcome attitudes that have made the working environment, in some instances, difficult for them.

The 4-6 work terms in the co-operative education program are an opportunity for female engineering students to not only practice engineering while pursuing their university program but also to interact with male engineers and reach a more representative decision or direction than would be otherwise reached in a male environment alone.
The Faculty of Engineering and Applied Science at Memorial University continues to recruit and retain more female engineering students and to inform them of the rapid changes in engineering and technology and the opportunities in design and manufacturing engineering for an exciting, rewarding and fulfilling career. Mechanical engineering and manufacturing are often represented by images of gears and other devices that represent strength, speed, and power to move objects or to transfer or generate power. Such images may be perceived as unattractive to females and they stand in contrast to the "angel of mercy" image of a nurse.

In general, females are often attracted to the "human side" of their work and programs and careers that involve client communication rather than spending time alone with computers and machinery [9]. The logos and graphics that have traditionally been used to represent and promote mechanical engineering can be changed to reflect and appeal to a broader constituency.

It is well known that "the medium is the message" and so the logo image, displays and advertising can be more made more attractive and appealing to female students. The images of gears, power, and strength of mechanical systems often do not contain a human as part of the image. These logo styles may provoke an image of muscular strength and overcoming the brute forces of nature. Such subconscious messages can mislead young girls to think that engineering is primarily for strong men. There are many engineering schools that use gears as a logo for mechanical and manufacturing engineering disciplines.

Images and graphics that could convey a human face of mechanical and manufacturing engineering are plentiful. For example, mechanical engineers are involved in the manufacture of artificial implants like composite materials used for heart valves, titanium alloys are used for hip joints, dental implants, or rescue vehicles. Among the reasons why females are attracted to biomedical engineering, is that a girl can imagine herself at some point in life being a patient losing one of his/her human organs and needing an artificial hip joint or skin replacement (tissue engineering). Such engineering applications address the quality of life following major life-changing injuries through better design and manufacturing of various assisting devices.

Mechanical and manufacturing engineering disciplines are a good focal point of other engineering discipline due to a wide range of sub disciplines as described earlier. Such varieties and a broad range of courses will encourage female students to enrol in mechanical and manufacturing engineering for various opportunities in an engineering career.

Hiring more female faculty members as role models is another important element to female recruitment and retention. It is very valuable for female students to 
have other women to whom they can relate and talk to about the challenges of being female in the engineering profession.

Regular visits to high schools by female faculty and students to encourage young girls to consider engineering and the opportunity to win engineering scholarships targeted to young female students are other positive steps that can be taken. It is encouraging and informative for female students to hear female engineers talk about their engineering work, especially those whose work has a clear human-to-human interaction (e.g. medical device industry, designing and manufacturing artificial implants, health and safety design for aerospace and automotive industries, etc.).

\section{MEMORIAL UNIVERSITY INITIATIVES}

Memorial's initiatives are focused on four main areas of a 5-year strategic plan to make engineering programs more attractive to a greater diversity of students and women in particular. These include: 1) recruitment and retention; 2) curriculum; 3) outreach activities; and 4) a supportive and respectful environment. For recruitment and retention, the plan entails personal letters from the Dean to young women who participate in summer programs so as to encourage them to consider engineering as a career. The Faculty is also collecting retention data by gender from First Year to Term 3, then analyzing this data to develop methods that improve student retention. With respect to curriculum, the plan includes studies of how the curriculum can be made more attractive to women. This involves increasing the exposure of students to social context, real-world problems, benefits to the community, and impact on society, particularly in First Year.

Outreach activities include an expanded effort to pursue high school outreach activities with the recruitment office and events with high school teachers. The plan aims to increase our participation in high school events involving math and science and work collaboratively with other groups including WISE (Women In Science and Engineering), GirlQuest and EWB (Engineers Without Borders).

A supportive and respectful environment is also a key element in retaining women in engineering programs. Female mentors will provided by pairing upper-class and graduate students with first year female students. The Faculty will also strive to ensure at least one female instructor in First Year courses. Efforts are also underway to build camaraderie and maximize chances for women to work together, for example, by having at least two females in a lab or project group and women engineering students together in residence. Finally, initiatives will raise awareness among all students to promote women and men working together in a professional environment to achieve better outcomes.

\section{CONCLUSIONS AND SUGGESTIONS}

Significant efforts have been invested at Memorial University in activities, programs, and scholarships to attract female students into engineering programs. There has been some progress but still work is needed to improve female enrolment. Focus areas to improve the recruitment and retention of women in engineering have been identified

The imagery used by engineering schools for mechanical engineering have not traditionally represented elements which attract women such as human communication and the positive impact of engineering on communities and society. To often the profession represents itself by images of computers, machines, and the devices that engineers produce (machines, power generation, and so forth).

With more female input into an engineering design, products can better represent and reflect the broader needs of society.

\section{Acknowledgements}

The author gratefully acknowledges the assistance of Dr. Greg Naterer, Dean of Engineering and Applied Science at Memorial University, and financial support from the Natural Sciences and Engineering Research Council of Canada (NSERC).

\section{References}

[1] http://www.ospe.on.ca/Newsroom/GlobeandMail_May [2] http://www.engineerscanada.ca/files/w_re port_enrolment_eng.pdf

[3] Adelman, C (1998), Women and Men of the Engineering Path: A Model for Analysis of Undergraduate Careers.

[4] Eccles-Parsons, J, Adler, TF, Futterman, R, Goff, SB, Kaczala, CM, Meece, JL, and Midgley, C (1985), Self-

Perceptions, Task Perceptions, Socializing Influences and the Decision to Enrol in Mathematics, pp. 95-122.

[5] Felder, RM, Felder, GN, Mauney, M, Hamrin, Jr, CE, and Dietz, JE (1995), A Longitudinal Study of Engineering Student Performance and Retention III. Journal of Engineering Education, pp. 151-163.

[6] Updegraff, KA, McHale, SM, and Crouter, AC (1996), Gender Roles in Marriage: What Do They Mean for Girls' and Boys' School Achievement? Journal of Youth and Adolescence, 25(1), pp. 73-89.

[7] http://www.iveyengineering.com/blog/famous-femaleengineers/

[8] Mcllwee, JS, and Robinson, JG (1992), Women in Engineering gender, power and workplace culture. State University of New York Press.

[9] Graham, A, Women in the Workforce (2014), The Best Careers for Women, pp. 1-1. 